\title{
Stratospheric aerosol particle size information in Odin-OSIRIS limb scatter spectra
}

\author{
L. A. Rieger, A. E. Bourassa, and D. A. Degenstein \\ Institute of Space and Atmospheric Studies, University of Saskatchewan, Saskatchewan, Canada \\ Correspondence to: L. A. Rieger (landon.rieger@usask.ca) \\ Received: 11 March 2013 - Published in Atmos. Meas. Tech. Discuss.: 7 June 2013 \\ Revised: 20 December 2013 - Accepted: 6 January 2014 - Published: 13 February 2014
}

\begin{abstract}
The Optical Spectrograph and InfraRed Imaging System (OSIRIS) onboard the Odin satellite has now taken over a decade of limb scatter measurements that have been used to retrieve the version 5 stratospheric aerosol extinction product. This product is retrieved using a representative particle size distribution to calculate scattering cross sections and scattering phase functions for the forward model calculations. In this work the information content of OSIRIS measurements with respect to stratospheric aerosol is systematically examined for the purpose of retrieving particle size information along with the extinction coefficient. The benefit of using measurements at different wavelengths and scattering angles in the retrieval is studied, and it is found that incorporation of the $1530 \mathrm{~nm}$ radiance measurement is key for a robust retrieval of particle size information. It is also found that using OSIRIS measurements at the different solar geometries available on the Odin orbit simultaneously provides little additional benefit. Based on these results, an improved aerosol retrieval algorithm is developed that couples the retrieval of aerosol extinction and mode radius of a log-normal particle size distribution. Comparison of these results with coincident measurements from SAGE III shows agreement in retrieved extinction to within approximately $10 \%$ over the bulk of the aerosol layer, which is comparable to version 5. The retrieved particle size, when converted to Ångström coefficient, shows good qualitative agreement with SAGE II measurements made at somewhat shorter wavelengths.
\end{abstract}

\section{Introduction}

Stratospheric aerosols play an important role in Earth's radiative balance and have been studied using numerous instruments. The Stratospheric Aerosol and Gas Experiment (SAGE) II, in particular, operated from 1984 to 2005, and has provided an invaluable record of high-quality, stable, global, long-term aerosol levels. This is in part due to the nature of occultation measurements, which provide an inherent calibration through measurement of the exo-atmospheric solar spectrum as well as direct measurements of atmospheric optical depth. After Rayleigh scattering and gaseous absorbers are accounted for, aerosol extinction can be computed from the residual signal. While these occultation measurements provide distinct advantages in terms of measurement simplicity, the technique also limits coverage, typically producing two measurements per orbit. Measurements of limbscattered sunlight have also been used to retrieve stratospheric aerosol extinction profiles. This technique aims to improve the global coverage while still providing relatively good vertical resolution. Satellite limb scatter instruments include the Optical Spectrograph and InfraRed Imaging System (OSIRIS) (Llewellyn et al., 2004), SAGE III (Rault, 2005; Rault and Loughman, 2007), the SCanning Imaging Absorption spectroMeter for Atmospheric CartograpHY (SCIAMACHY) (Bovensmann et al., 1999) and the Ozone Mapping and Profiler Suite (OMPS) (Rault and Loughman, 2013).

These limb scatter instruments measure vertical profiles of integrated line of sight radiance, typically at a wide range of wavelengths from the UV to the near infrared. As mentioned, this allows for the opportunity to measure any sunlit portion of the globe, greatly improving coverage. The cost of these 
measurements comes in the increased complexity. Light that has been scattered multiple times must be accounted for, requiring complex forward model calculations to perform retrievals. This is particularly difficult for aerosols due to the signal dependence on microphysical properties in addition to particle number density, and requires the assumption or retrieval of aerosol size parameters in addition to extinction coefficients.

This work focuses on measurements made by the OSIRIS instrument, which was launched in February 2001 onboard the Odin satellite and continues full operation to the time of writing. Odin is in a polar, Sun-synchronous orbit at approximately $600 \mathrm{~km}$ with an inclination of $98^{\circ}$. OSIRIS views in the orbital plane and this provides measurements from $82^{\circ} \mathrm{S}$ to $82^{\circ} \mathrm{N}$ with equatorial crossings at 18:00 LT and 06:00 LT for the north- and southbound crossings, respectively. Orbital precession has caused the local time to increase by approximately 1 hour over the duration of the mission. As Odin orbits the satellite nods to scan the instrument line of sight vertically at tangent heights from the upper troposphere to the mesosphere.

The optical spectrograph measures wavelengths from 274 to $810 \mathrm{~nm}$ with $1 \mathrm{~nm}$ resolution along a single line of sight, with a vertical sampling rate of $2 \mathrm{~km}$ and vertical resolution of approximately $1 \mathrm{~km}$. As Odin is scanned this provides vertical information from approximately 7 to $65 \mathrm{~km}$ during normal aeronomy operations. The infrared imager is composed of three vertical photodiode arrays, each with 128 pixels, with filters on each channel of 1260, 1270 and $1530 \mathrm{~nm}$. The measurement technique of the infrared imager is fundamentally different than that of the optical spectrograph; each pixel measures a line of sight at a particular altitude, creating an entire vertical profile spanning tangent heights over approximately $100 \mathrm{~km}$ with each exposure. As the satellite nods, the imaged altitude range is then shifted. Due to the altitude range of the infrared imager, the majority of measurements in a scan image the entirety of the stratosphere.

A stratospheric aerosol retrieval was developed for use with the OSIRIS measurements by Bourassa et al. (2007). This algorithm uses a spectral ratio as the retrieval vector and the SASKTRAN forward model for radiative transfer calculations (Bourassa et al., 2008b). Scattering cross sections and phase functions used in the radiative transfer model are calculated from an assumed representative particle size distribution. The inversion is performed using the multiplicative algebraic relaxation technique, which has also been implemented in the successful retrieval of ozone (Degenstein et al., 2009) and nitrogen dioxide (Bourassa et al., 2011) from the OSIRIS measurements. Further improvements to the aerosol algorithm, including a more sensitive aerosol measurement vector and coupled albedo retrieval, were implemented in the version 5 algorithm and are discussed in detail by Bourassa et al. (2012). Herein a brief overview of the version 5 algorithm is given, and the systematic effects of the assumed particle size distribution are discussed. In Sect. 3, the sensitivity and information content of OSIRIS measurements in relation to particle size is explored to provide a foundation for an improved retrieval. Section 4 provides a development of this improved retrieval, which couples the aerosol extinction retrieval and retrieval of a particle size parameter. Here the retrieval sensitivity and error are also examined. In Sect. 5 the improved algorithm is applied to the OSIRIS data for the full mission time series and results are compared against version 5 as well as SAGE II and III measurements. Finally, conclusions are discussed in Sect. 6.

\section{Version 5 algorithm}

The stratospheric aerosol extinction coefficient at $750 \mathrm{~nm}$, which is currently retrieved as part of the standard OSIRIS data processing, uses an assumed unimodal log-normal particle size distribution of the form

$$
\frac{\mathrm{d} n(r)}{\mathrm{d} r}=\frac{n_{\mathrm{aer}}}{r \ln \left(\sigma_{g}\right) \sqrt{2 \pi}} \exp \left(-\frac{\left(\ln r-\ln r_{g}\right)^{2}}{2 \ln \left(\sigma_{g}\right)^{2}}\right) .
$$

This provides a distribution with a single peak (or mode) where the number of particles is normally distributed according to the logarithm of particle radius. Aerosol concentration is then fully described by three parameters: mode radius, $r_{g}$; mode width, $\sigma_{g}$; and the total number of particles, $n_{\text {aer }}$; for each mode. For the version 5 algorithm, a unimodal distribution with a mode radius of $80 \mathrm{~nm}$ and mode width of 1.6 is assumed, as these are typical of the background aerosol loading conditions (Deshler et al., 2003). The scattering cross sections and phase functions are then calculated using Mie theory assuming an aerosol consisting of $25 \% \mathrm{H}_{2} \mathrm{O}$ and $75 \%$ $\mathrm{H}_{2} \mathrm{SO}_{4}$, and aerosol number density is retrieved using a single measurement vector based on the ratio of spectral radiances at two wavelengths

$\tilde{I}(j)=\frac{I(j, 750 \mathrm{~nm})}{I(j, 470 \mathrm{~nm})}$,

where $j$ denotes the tangent altitude index. This normalization is used to reduce the effect of local density fluctuations in the neutral background, which would otherwise be fitted with the aerosol concentration, and to increase sensitivity to the Mie scattering signal (Bourassa et al., 2007). To further increase the sensitivity to aerosol, the measurement is normalized by a modelled Rayleigh signal, $\tilde{I}_{\text {Ray }}(j)$, yielding

$y_{j}=\ln \left(\frac{\tilde{I}(j)}{\tilde{I}_{\text {Ray }}(j)}\right)$.

The Rayleigh signal is computed using SASKTRAN on a scan-by-scan basis assuming an aerosol-free atmosphere. Particularly at low altitudes, the bulk of the scattered signal is due to Rayleigh scattering. Normalizing by the Rayleigh signal (note that it is a subtraction in log space) largely removes the Rayleigh contribution, creating a measurement 
vector much more linearly dependent on the aerosol loading. Finally, the measurement vector is normalized by a set of high-altitude measurements above the aerosol layer using the geometric mean. This eliminates the need for an absolute calibration and decreases the sensitivity to unknown surface albedo and tropospheric clouds (von Savigny et al., 2003). For a more detailed description of the aerosol measurement vector, see Bourassa et al. (2012). This provides the final aerosol measurement vector

$y_{j}=\ln \left(\frac{\tilde{I}(j)}{\tilde{I}_{\text {Ray }}(j)}\right)-\frac{1}{N} \sum_{j=m}^{m+N} \ln \left(\frac{\tilde{I}(j)}{\tilde{I}_{\text {Ray }}(j)}\right)$,

where $N$ tangent altitudes between $m$ and $m+N$ have been used for the normalization. Typically, normalization occurs between 35 and $40 \mathrm{~km}$ in the tropics and closer to $30 \mathrm{~km}$ at higher latitudes.

Using radiance measurements in the normalization range, the $750 \mathrm{~nm}$ albedo is retrieved assuming a Lambertian surface and by iteratively matching the measured and modelled radiances. The retrieved atmospheric state, $\hat{\boldsymbol{x}}$, is then updated using the multiplicative algebraic reconstruction

$\hat{x}_{i}^{(n+1)}=\hat{x}_{i}^{(n)} \sum_{j} \frac{y_{j}^{\mathrm{obs}}}{y_{j}^{\mathrm{mod}}} W_{i j}$.

Here, $\hat{\boldsymbol{x}}$ is simply the aerosol extinction profile, as that is the only retrieved aerosol parameter. The weighting matrix, $\mathbf{W}$, provides the contribution of various lines of sight at tangent altitudes, $j$, to the retrieved altitude, $i$, based on relative path lengths of the line of sight through the spherical shells. Further details on the MART method and the determination of the weighting factors, $W_{i j}$, are provided in Bourassa et al. (2007), Bourassa et al. (2012) and Degenstein et al. (2004, 2009). Although the albedo is retrieved prior to aerosol extinction, it is sensitive to the aerosol loading and is retrieved again after the aerosol retrieval has converged. Aerosol is then retrieved again with the updated albedo value.

The limitation of this approach is that the measurement vector, $\boldsymbol{y}$, is dependent upon the aerosol phase function, which is dictated by the assumed particle size. Any bias in the assumed phase function is translated to the retrieved extinction. The effect of this can be tested by comparing data taken at similar locations and times, but with different viewing geometries. If the particle size, and thus the phase function, is correct, then measurements will be independent of the solar scattering angle and match to within atmospheric variability. If, on the other hand, particle size has been incorrectly assumed, this will be reflected in the phase function, and the retrieval will compensate with differing amounts of aerosol depending upon the solar scattering angle. It is possible to test this dependence through the comparison of retrievals at similar locations and times, but with different solar scattering angles. An example of two such measurements that occur for OSIRIS, one on the ascending track of the orbit and

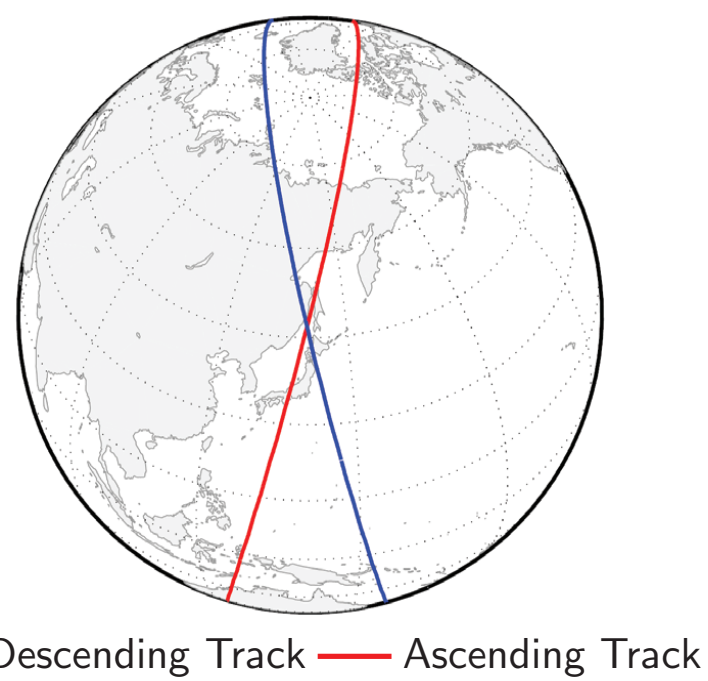

Fig. 1. OSIRIS often measures the same location twice over the course of $12 \mathrm{~h}$ due to orbit. Here an example of an ascending track is shown in red and a descending track in blue. The crossing point is the matched pair of scans, 11222020 and 11229004 , where the same location was measured twice, approximately $12 \mathrm{~h}$ apart and with different viewing geometries.

a second on the descending track, is shown in Fig. 1. The crossing point of the two tracks occurs approximately $12 \mathrm{~h}$ apart, with scattering angles that differ by up to $60^{\circ}$ in the tropics, depending upon the season. Provided diurnal variation of aerosol is minimal, this provides an excellent test of the phase function.

A comparison of ascending and descending track measurements using weekly averages is shown in Fig. 2 for two latitude bands: $20^{\circ} \mathrm{N}$ to $20^{\circ} \mathrm{S}$ is shown in the left column and $40^{\circ} \mathrm{N}$ to $60^{\circ} \mathrm{N}$ in the right. The ascending- and descendingnode scattering angles are shown in the top panels, and the weekly aerosol extinction ratios at several altitude levels are shown in the bottom panels for the respective orbital tracks. After 2006, the local time of the ascending node increases past that of local sunset due to orbital precession and the tangent point is no longer sunlit in the tropics. A systematic difference is apparent between the ascending and descending tracks in the tropics that correlates well with the difference in scattering angles, indicating that the phase function and assumed particle size distribution are likely incorrect. At mid-latitudes the comparisons are quite a bit better, with much smaller differences between ascending and descending nodes. Similarly, lower altitudes tend to fair better and the reason for this is three-fold:

- The OSIRIS scattering angles have the largest separation in the tropics due to the Odin orbit. 


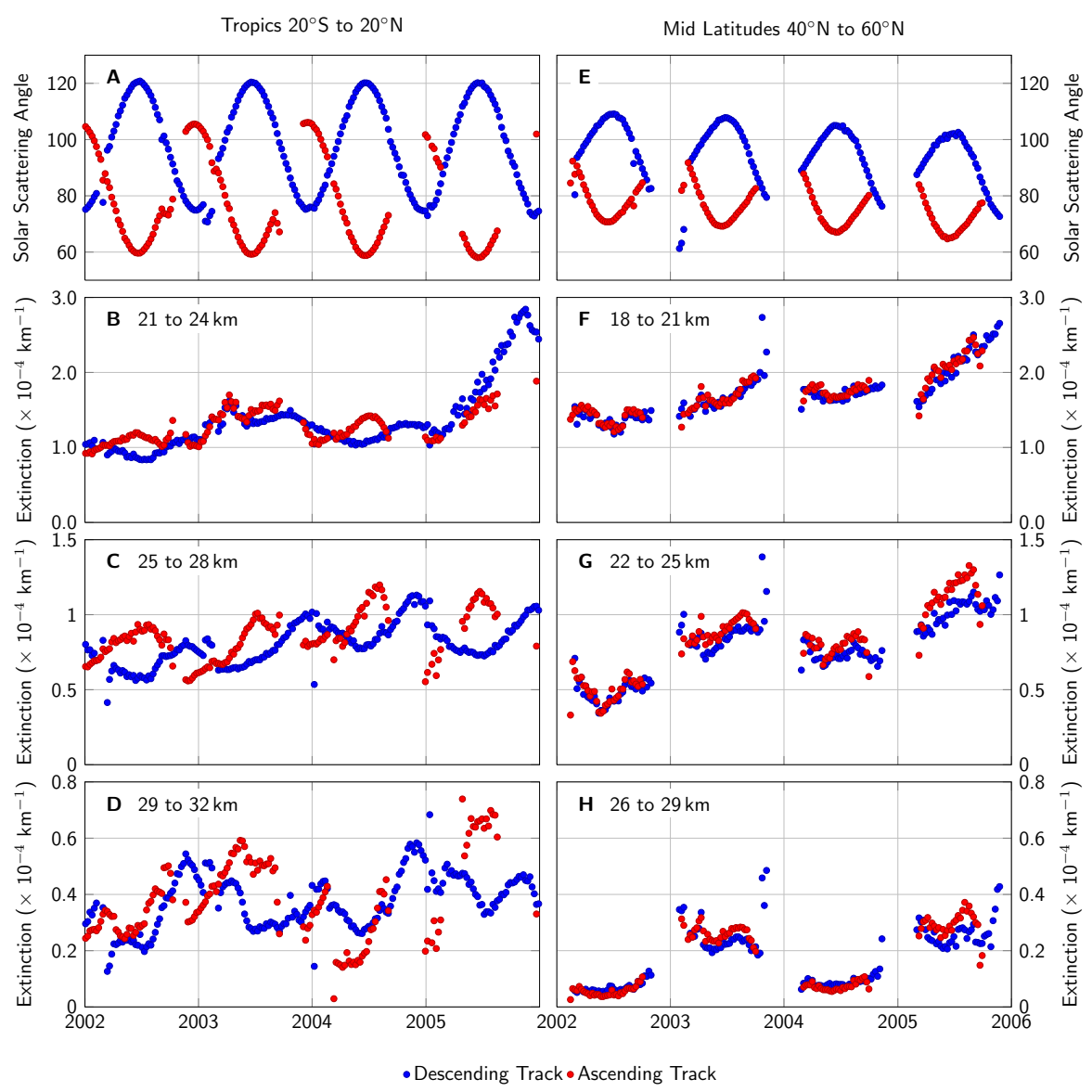

Fig. 2. Retrieved extinction on the ascending and descending measurement tracks. Panel (A) shows the weekly averaged solar scattering angle of the ascending and descending track measurements from $20^{\circ} \mathrm{N}$ to $20^{\circ} \mathrm{S}$. Panel (E) shows the same results for $40^{\circ} \mathrm{N}$ to $60^{\circ} \mathrm{N}$. Panels (B) through (D) show the retrieved extinction at various altitudes for the two measurement tracks in the tropics. Panels (F) through (H) show the same results for the mid-latitudes at slightly lower altitudes.

- Low stratospheric altitudes have higher contributions of multiple scattering, helping to minimize the effects of incorrect phase functions.

- Higher latitudes have particle sizes more similar to the assumed particle size of $80 \mathrm{~nm}$ mode radius and 1.6 mode width as this distribution was based on the midlatitude measurements by Deshler et al. (2003).

Removal of this bias requires more accurate estimation of the particle size parameters used in the SASKTRAN model, and the following section discusses the information available from OSIRIS to retrieve particle size directly.

\section{OSIRIS information content}

In version 5 the normalization of the $750 \mathrm{~nm}$ radiance by the radiance at $470 \mathrm{~nm}$ was beneficial in minimizing the effect of uncertainty in the local air density. However, the $470 \mathrm{~nm}$ measurements are not completely insensitive to aerosol, particularly smaller particles, and for the purposes of retrieving particle size information, this spectral normalization creates a more non-linear solution space and increases the difficulty of the retrieval. This effect can be seen in Fig. 3, where the aerosol measurement vector was modelled for a variety of extinctions and particle sizes, both with and without the $470 \mathrm{~nm}$ normalization. As a function of extinction the measurement vectors are well behaved, showing a roughly linear response. However, the normalized vector shows poor response as a function of both mode radius and width, with multiple solutions under certain conditions and little sensitivity to small particles. In particular, the un-normalized measurement vector is much more sensitive to smaller mode radii than the normalized version. This will become important in Sect. 4, where a retrieval algorithm is developed which retrieves mode radii. Therefore, in this work the $470 \mathrm{~nm}$ normalization is removed from the aerosol measurement vector. 

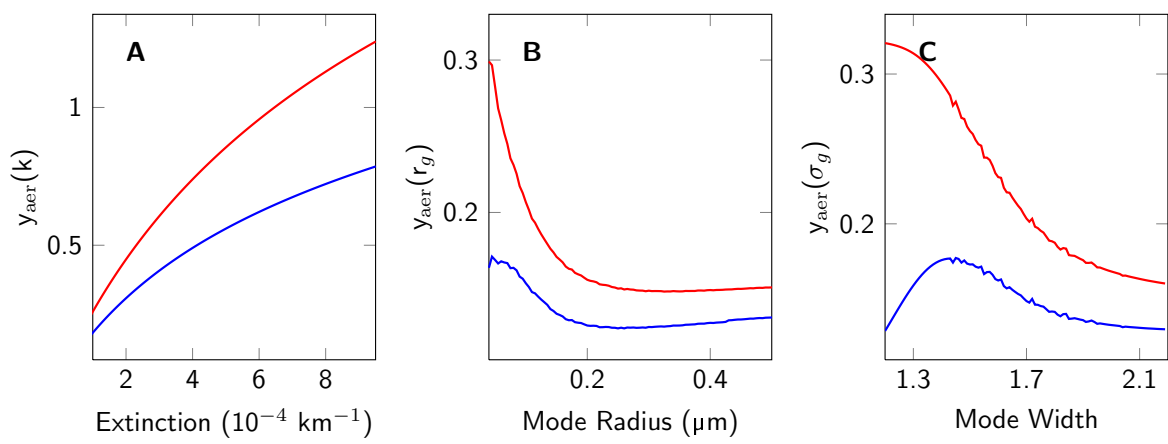

— Normalized _ Unnormalized

Fig. 3. Response of the normalized (blue) and un-normalized (red) measurement vectors at $25 \mathrm{~km}$ to changes in aerosol parameters for a scan with a solar zenith angle of $70^{\circ}$ and solar scattering angle of $90^{\circ}$. (A) shows the measurement vectors as a function of extinction with a mode radius of $80 \mathrm{~nm}$ and mode width of 1.6. (B) shows the response as a function of mode radius given a mode width of 1.6 and extinction of $1 \mathrm{e}-4 \mathrm{~km}^{-1}$. (C) shows the response as a function of mode width given a mode radius of $80 \mathrm{~nm}$ and extinction of $1 \mathrm{e}-4 \mathrm{~km}{ }^{-1}$.

The single wavelength measurement vector is then

$y_{j}=\ln \left(\frac{I(j, \lambda)}{I_{\text {Ray }}(j, \lambda)}\right)-\frac{1}{N} \sum_{j=m}^{m+N} \ln \left(\frac{I(j, \lambda)}{I_{\text {Ray }}(j, \lambda)}\right)$.

Note here that for a given wavelength this is similar to Eq. (4), except that $\tilde{I}(j, \lambda)$ has been replaced with the unnormalized $I(j, \lambda)$. We now explore the particle size information contained in measurement vectors of this type for the full set of wavelengths measured by OSIRIS.

To extract particle size information from the wavelength dependence of OSIRIS measurement vectors, the wavelength dependence of the measurement vector due to changing particle size must be considerably larger than the measurement noise. This dependence is explored by simulating the aerosol measurement vector for multiple wavelengths and particle sizes using SASKTRAN. This was done by assuming three different size distributions and extinctions which produce the same $750 \mathrm{~nm}$ measurement vector; that is, three atmospheric states which are essentially indistinguishable with a single wavelength retrieval at $750 \mathrm{~nm}$. The first is a bimodal distribution meant to simulate volcanic conditions; the second is a "fine-mode" distribution, used in the version 5 retrievals and corresponding to a typical background state; and the third is a single-mode "representative" distribution with the same effective radius as the bimodal distribution. Particle size distribution parameters are give in Table 1. These are shown in panel a of Fig. 4. The resulting aerosol measurement vectors were then modelled at a range of wavelengths for an OSIRIS scan with a scattering angle of $60^{\circ}$ and solar zenith angle of $79^{\circ}$ and are shown in Fig. 14b. The change of the measurement vector for the three cases then indicates the sensitivity to particle size. Figure 4 shows that the measurement vectors above approximately $800 \mathrm{~nm}$ provide good sensitivity to particle size, with differences of more than $30 \%$ at $1500 \mathrm{~nm}$ for the cases studied here. Panel c shows the relative difference between cases when compared to the bimodal state. The relative error in the bimodal measurement vector due to a $1 \%$ error in radiance is shown as the shaded grey region; this is typical of the error for $750 \mathrm{~nm}$ OSIRIS measurements.

A broader study of wavelength sensitivity was performed for a number of geometries and particles size distributions assuming a mode width of 1.6, with results shown in Fig. 5. Again, number densities were chosen such that measurements at $750 \mathrm{~nm}$ would be the same. Six geometries at the full range of OSIRIS solar scattering and zenith angles were tested with mode radii ranging from 0.04 to $0.14 \mu \mathrm{m}$. In forward-scattering conditions $\left(\mathrm{SSA}=60^{\circ}\right.$ ) wavelengths below $750 \mathrm{~nm}$ show some sensitivity to particle distributions with small mode radii; however the difference is small compared to the longer wavelengths, where substantial differences between particle sizes can be seen. This is similar for the other geometries, where longer wavelengths show much better sensitivity to particle size for all size distributions tested here.

As the optical spectrograph only measures out to $800 \mathrm{~nm}$, inclusion of the infrared imager is highly beneficial when attempting particle size retrievals. The imager channels at 1260 and $1270 \mathrm{~nm}$ were designed to measure excited-state oxygen emission, and this emission renders these channels unusable for aerosol retrieval; however, the $1530 \mathrm{~nm}$ channel, which was designed to measure an excited $\mathrm{OH}$ emission that is extremely weak during daytime, can be used for the aerosol retrieval. A proof-of-concept particle size retrieval using a combination of OSIRIS spectral measurements and a simple two-step retrieval is presented in Bourassa et al. (2008a). A different algorithm which assumes a constant size profile is presented by Rault and Loughman (2013) for use with the OMPS data. Here we explore the full potential of the particle size information in the OSIRIS measurements and compare these new results with the SAGE II and III measurements. 

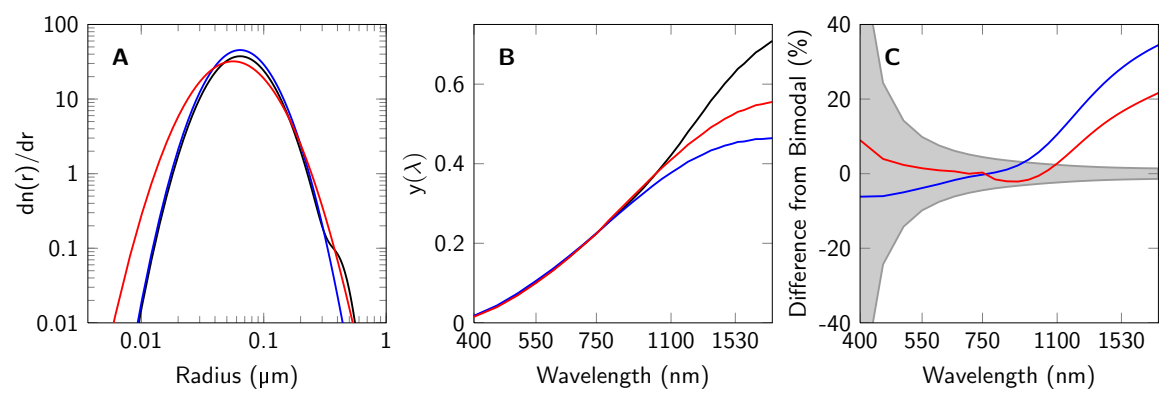

— Bimodal — Fine Mode — Representative

Fig. 4. Modelled sensitivity of the aerosol measurement vectors from scan 6432001 as a function of wavelength for three particle size distributions at $22.5 \mathrm{~km}$. (A) shows the size distributions at $22.5 \mathrm{~km}$, with parameters listed in Table 1. (B) shows the measurement vectors as a function of wavelength for the three distributions. (C) shows the relative difference between the measurement vectors compared to the bimodal state. The shaded area shows error in the bimodal measurement vector due to $1 \%$ error in the measured radiance.

Table 1. Particle size distributions at $22.5 \mathrm{~km}$ used to create Fig. 4.

\begin{tabular}{lrrrr}
\hline & \multirow{2}{*}{ Fine Mode } & Representative & \multicolumn{2}{c}{ Bimodal } \\
\cline { 4 - 5 } & & & Fine Mode & Course Mode \\
\hline Number Density $\left(\mathrm{cm}^{-3}\right)$ & 4.0 & 3.0 & 3.2 & 0.012 \\
Mode Radius $(\mathrm{nm})$ & 80 & 77 & 80 & 400 \\
Mode Width & 1.6 & 1.75 & 1.6 & 1.2 \\
\hline
\end{tabular}

Figure 2 shows that particle size information is also apparent when comparing measurements at different scattering angles. However, the spectral and geometric pieces of information are not independent, and the ability to derive multiple pieces of information depends on both the sensitivity of the measurement vectors to particles of different sizes and the instrument noise. The sensitivity to particles of a specific size can be estimated by simulating measurements for a range of monodisperse droplets sizes. This is computed in SASKTRAN by assuming an aerosol profile and keeping the aerosol volume constant at each altitude as particle size is changed. At each particle size the measurement vectors are modelled to determine their sensitivity. Note that when included in a size distribution, the response will be slightly different due to multiple-scattering effects between aerosol particles; particles of different sizes will change the diffuse radiance slightly, altering the sensitivity to particles of a given size. However this effect is typically small for background aerosol loading at these wavelengths, where Rayleigh and ground scatter dominate the distribution of radiation in the diffuse field. The kernel will also depend slightly on the profile chosen; however due to the nature of limb measurements the bulk of the signal comes only from the tangent point shell. For reference, a simple single-scatter approximation can also be analysed. Ignoring both multiple scatter and attenuation along the line of sight, the signal due to aerosol is proportional to the extinction, $k_{\text {aer }}$, and the aerosol phase function, $p\left(\Theta_{k}, \lambda_{k}, r\right)$ at the tangent point. The kernel, $K$, at wavelength $k$, is then

$K_{k}(r)=\frac{3}{4 \pi r^{3}} \sigma_{\mathrm{aer}}\left(\lambda_{k}, r\right) p\left(\Theta_{k}, \lambda_{k}, r\right) \Delta s$,

where $\sigma_{\text {aer }}$ is the aerosol scattering cross section and $\Delta s$ is the path length through the tangent point shell. The derivation of this kernel is shown in Appendix A. Both the single- and multiple-scatter kernels were computed for a matched pair of scans with solar zenith angles of $89^{\circ}$ and $83^{\circ}$ and solar scattering angles of $60^{\circ}$ (forward scattering) and $118^{\circ}$ (backscattering). Kernels for these geometries at 750 and $1530 \mathrm{~nm}$ are shown in Fig. 6. Although the multiple-scatter kernels tend to be smoothed compared to the single scatter, agreement between them is still quite good, indicating that the singlescatter component dominates the sensitivity of the measurement to particle size at these geometries. Agreement also shows that the precise profile chosen for the multiple-scatter analysis is not overly important for this sensitivity study.

As expected, the shorter wavelengths show increased sensitivity to smaller particles; however the scattering angle plays an important role as well, tending to shift the peak sensitivity to larger particles as scattering angle is decreased. $\mathrm{Al}-$ though not identical this gives the $750 \mathrm{~nm}$ backscatter measurement similar sensitivity to the $1530 \mathrm{~nm}$ forward-scatter measurement. This suggests that while particle size information is present in the scattering angle dependence of the measurements, it may largely overlap with the information contained in the wavelength dependence of the measurements. 


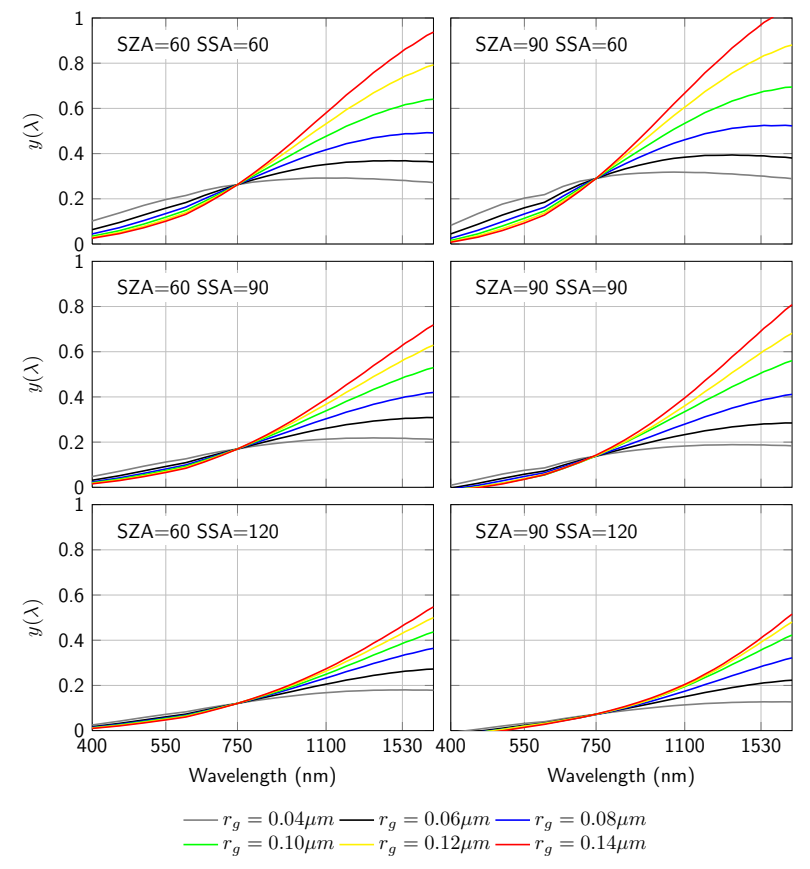

Fig. 5. Modelled sensitivity of the aerosol measurement vectors for a variety of geometries, and particle size distributions as a function of wavelength. The solar scattering angle (SSA) and solar zenith angle (SZA) of the simulated measurements are shown in the corner of each panel. The particle size distributions were assumed to be unimodal log-normal, with a mode width of 1.6 and mode radius given in the legend.

To test the degree of unique information contained in the four measurements, the analysis described by Twomey (1977) can be employed. This technique was also used by Thomason and Poole (1992) and Thomason et al. (1997) in determining particle size properties from the SAGE II data. Although limb scatter measurements are fundamentally different than occultation, the similarity of the single- and multiple-scatter kernels in Fig. 6 show that the sensitivity can be well understood by examining single-scatter kernels. In fact, we can do better than this by using the multiple-scatter kernels, although these still neglect aerosol-to-aerosol scattering effects as mentioned above.

The covariance of the kernels is a measure of their orthogonality, and if any eigenvalues of the covariance matrix are zero, then the measurement is repetitive. Eigenvalues are then a measure of the new information contained in the each measurement. For the multiple-scatter kernels in Fig. 6 the eigenvalues are

$1.000, \quad 0.0807, \quad 0.0425, \quad 0.0144$

While all measurements contain some new information, the addition of a second geometry is of decreasing benefit, with the majority of the information contained in the first two measurements. This also shows that while inversions are

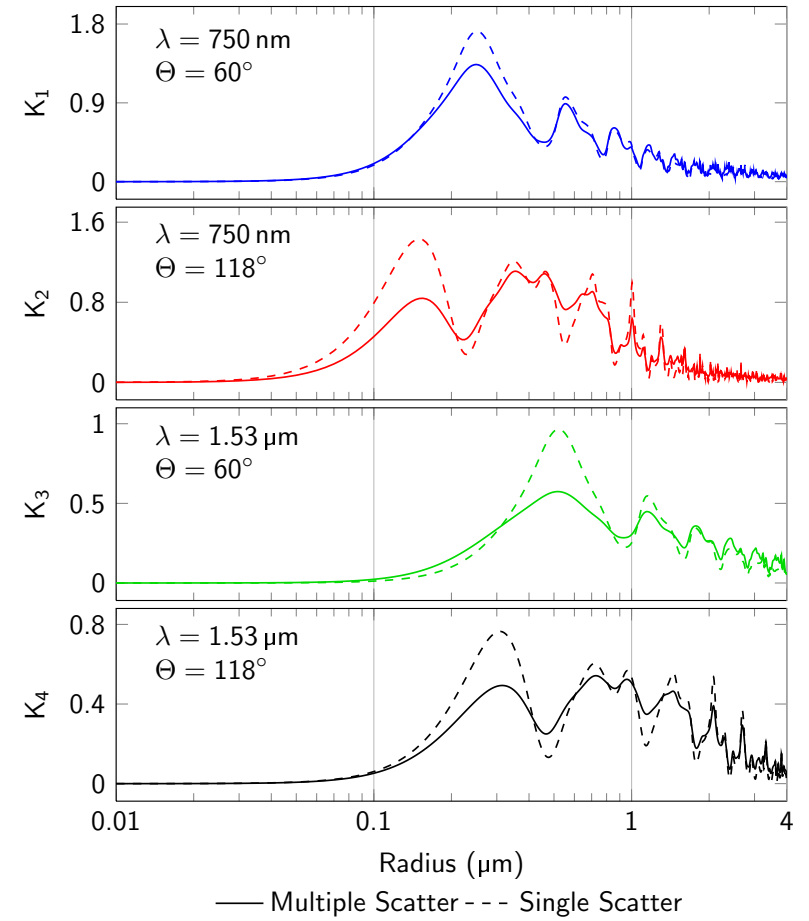

Fig. 6. Simulated measurement vector kernels for a matched pair of scans at $22.5 \mathrm{~km}$ for a range of mono-disperse particles with radius $r$. The wavelength, $\lambda$, and solar scattering angle, $\Theta$, of each measurement vector is given in the top left of the panels. Solid lines are the kernels calculated using the multiple-scattering SASKTRAN forward model, while the dashed curves show the kernels calculated from Eq. (7). Area has been normalized to one for all kernels.

sensitive to the choice of particle size, even the the second measurement contains only a small amount of additional information at these wavelengths, highlighting the need for accurate models and instruments with good signal-to-noise ratios. A more detailed application of this technique is available in Rieger (2013, Chap. 4.1); however the conclusions are the same. Even under ideal conditions, the incorporation of a second measurement at a different scattering adds only a small amount of additional information, while substantially reducing sampling and limiting geographic coverage. For these reasons the retrieval implemented below uses two wavelengths at a single geometry to retrieve one piece of particle size information.

\section{Coupled extinction and particle size retrieval}

To utilize the two pieces of information we maintain the assumption of a unimodal log-normal distribution with a mode width of 1.6 and attempt to retrieve mode radius and extinction using measurement vectors at 750 and $1530 \mathrm{~nm}$ as defined in Eq. (6). The model is initialized with the version 5 results to provide a rough estimate of extinction before mode 
radius is altered. This helps to avoid falling into an unrealistic local minimum of very few, very large particles and helps speed up convergence time. At each iteration, the mode radius and extinction are updated at each tangent altitude using the Levenberg-Marquardt algorithm (Marquardt, 1963),

$$
\left(\mathbf{J}_{j}^{T} \mathbf{J}_{j}+\gamma \operatorname{diag}\left(\mathbf{J}_{j}^{T} \mathbf{J}_{j}\right)\right) \boldsymbol{\delta}_{j}=\mathbf{J}_{j}^{T}\left(\boldsymbol{y}_{j}^{\text {mod }}-\boldsymbol{y}_{j}^{\text {obs }}\right),
$$

where $\mathbf{J}_{j}$ is the Jacobian at altitude $j$,

$\mathbf{J}_{j}=\left(\begin{array}{ll}\frac{\partial y_{j}(750 \mathrm{~nm})}{\partial r_{g}} & \frac{\partial y_{j}(750 \mathrm{~nm})}{\partial n_{\text {aer }}} \\ \frac{\partial y_{j}(1.53 \mu \mathrm{m})}{\partial r_{g}} & \frac{\partial y_{j}(1.53 \mu \mathrm{m})}{\partial n_{\text {aer }}}\end{array}\right)$.

The atmospheric state is then updated using

$\hat{\boldsymbol{x}}_{j}^{(n+1)}=\hat{\boldsymbol{x}}_{j}^{(n)}+\boldsymbol{\delta}_{j}$,

where $\hat{\boldsymbol{x}}$ includes both aerosol extinction and mode radii. The damping factor, $\gamma$, is initialized to 0.02 for the first iteration. If the mean square residual is improved after an iteration, $\gamma$ is left unchanged; if the residual grows, then $\gamma$ is increased by a factor of 10 and the iteration is retried. To improve computation time the Jacobians are computed only approximately. These are calculated by perturbing the entire vertical profile, calculating the new measurement vectors, and comparing the changes at each altitude. However, due to altitude coupling, part of the change at a given altitude will be due to the change in the profile above and below, typically causing a slight overestimation of the Jacobian. This increases the required number of iterations but greatly reduces the number of forward model calculations and improves the overall speed significantly. A profile is said to converge if the mean square residual is less than $4 \times 10^{-4}$. This criterion was chosen as it is close to the measurement vector noise and typically results in convergence by about 10 iterations. Iterations are stopped if the mean square residual falls below 1e-4 or more than 12 iterations have been performed.

\subsection{Retrieval simulations}

To test the proposed algorithm, several hundred retrievals were simulated at different OSIRIS geometries. To include the effects of incorrect particle size assumptions, a true state was chosen that was largely bimodal with a fine mode with a mode radius of $90 \mathrm{~nm}$ and mode width of 1.75 . The second, coarse mode of particles was given a mode radius of $400 \mathrm{~nm}$ and mode width of 1.2. The peak $750 \mathrm{~nm}$ aerosol extinction was set to be $7 \times 10^{-4} \mathrm{~km}^{-1}$, with approximately half of this coming from the coarse mode. As altitude increases, this fraction decreases. The retrieved aerosol was assumed to have a single mode of particles with a mode width of 1.6. The a priori state was assumed to have a mode radius of $80 \mathrm{~nm}$ and very small extinction - the same a priori used in the version 5 algorithm. Simulated retrievals were performed for 765 OSIRIS measurements with a variety of scattering

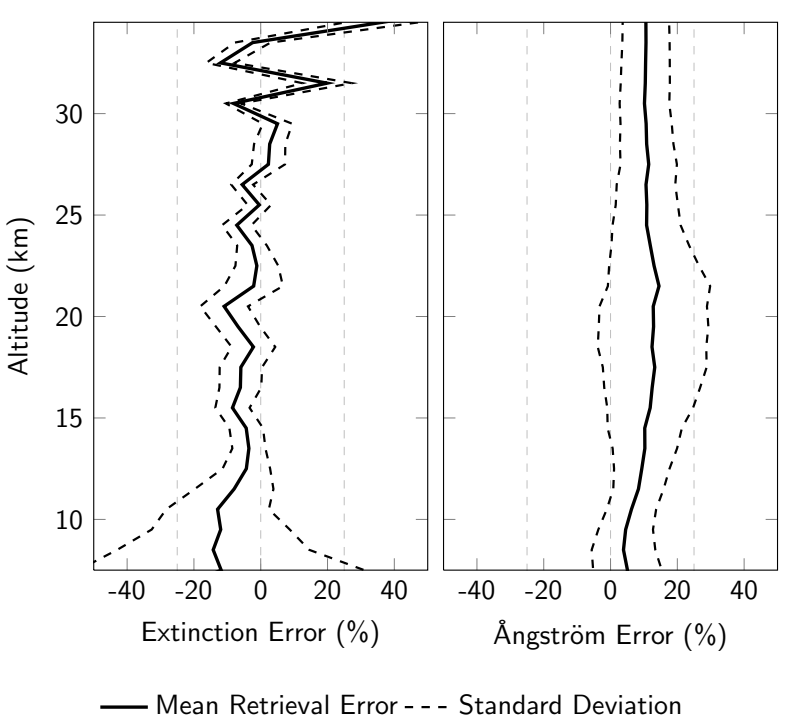

Fig. 7. Error in the retrieved parameters under a variety of simulated measurement conditions when the true atmospheric state is bimodal. Error using the coupled extinction and mode radius retrieval are shown in black, with dashed lines showing the standard deviation.

and zenith angles. Because the retrieved mode radius will be sensitive to assumed mode width, the mode radius is converted to the Angström coefficient, $\alpha$, which is an empirical relationship between the aerosol cross section at two wavelengths (Ångström, 1964),

$\frac{\sigma_{\mathrm{aer}}\left(\lambda_{1}\right)}{\sigma_{\mathrm{aer}}\left(\lambda_{0}\right)}=\left(\frac{\lambda_{1}}{\lambda_{0}}\right)^{-\alpha}$

This helps to reduce the dependence on the assumed mode width. The mean error and standard deviation of the retrieved extinction and Ångström coefficient are shown in Fig. 7. Error in the retrieved extinction was typically $5-10 \%$, with an error in the Ångström coefficient of $10-15 \%$. This shows that even under largely bimodal conditions the coupled retrieval of extinction and mode radius produce robust results with little bias and only a slight dependence on measurement geometry. Comparatively, performing the same simulated cases using the version 5 algorithm produces errors of $30 \%$ in extinction. Although this analysis includes only error due to microphysical assumptions, the error due to other factors can be estimated from the error analysis developed by Rodgers (2000, Chap. 3), which is broken into forward model error, measurement error and smoothing error. These are discussed in detail in the following sections and the error is simulated for a typical scan.

\subsection{Measurement error}

The measurement error can be broken into two components, a random error: $\delta \boldsymbol{y}_{\mathrm{R}}$, due to the measurement noise that is 
uncorrelated between altitudes, and a systematic error, $\delta y_{\mathrm{S}_{k}}$, due to the high-altitude normalization that is entirely correlated between altitudes. The random error in the measurement vector $\boldsymbol{y}_{k}$ at altitude $j$ can be determined from error in the spectral radiance measurement as

$\delta y_{\mathrm{R}_{k j}}=\frac{\delta I_{j}\left(\lambda_{k}\right)}{I_{j}\left(\lambda_{k}\right)}$.

Since the high-altitude normalization results in a shift of the measurement vector based on the spectral radiance measurements at high altitudes, the systematic error is the same for all altitudes and given by

$\delta y_{\mathrm{S}_{k}}=\frac{1}{N} \sqrt{\sum_{j=m}^{m+N} \frac{\delta I_{j}^{2}\left(\lambda_{k}\right)}{I_{j}^{2}\left(\lambda_{k}\right)} .}$

Following the error analysis by Barlow (1989) the random and systematic errors are independent, and thus the total variance of a measurement vector at altitude $j$ is simply the quadrature sum of both errors

$\delta y_{k j}^{2}=\delta y_{\mathrm{R}_{k j}}^{2}+\delta y_{\mathrm{S}_{k}}^{2}$.

The covariance of the errors can be found similarly; however the random errors will cancel, leaving only the squared systematic terms. The error covariance matrix, $\mathbf{S}_{\epsilon}$, for wavelength $k$ is then

$\mathbf{S}_{\epsilon_{k}}=\left(\begin{array}{ccc}\delta y_{\mathrm{R}_{k 1}}^{2}+\delta y_{\mathrm{S}_{k}}^{2} & \cdots & \delta y_{\mathrm{S}_{k}}^{2} \\ \vdots & \ddots & \vdots \\ \delta y_{\mathrm{S}_{k}}^{2} & \cdots & y_{\mathrm{R}_{k j}}^{2}+\delta y_{\mathrm{S}_{k}}^{2}\end{array}\right)$.

From here, the gain matrices, $\mathbf{G}=\frac{\delta \hat{\boldsymbol{x}}}{\delta \boldsymbol{y}}$, are computed numerically by perturbing the measurement vector at a particular altitude and simulating a retrieval. The error in the retrieved quantities is then given by the diagonal of

$\mathbf{S}=\mathbf{G S}_{\epsilon} \mathbf{G}^{T}$.

Measurement errors for the optical spectrograph and infrared imager are quite different due to the measurement techniques. As the optical spectrograph is scanned vertically, the exposure time can be increased, resulting in approximately the same number of photons being counted with each exposure; this results in noise that increases only slightly with altitude, ranging from approximately $0.5-1 \%$ of the total signal. The IR channels image the entire vertical profile simultaneously, resulting in considerable noise at higher altitudes, typically of the order of $10 \%$. Fortunately, the imager takes multiple profiles for each optical spectrograph scan, often 30 or more, which can be collapsed into an average profile to reduce the noise. Despite this averaging, error in the infrared channel still exceeds that of the optical spectrograph. This produces a measurement vector error of approximately $5 \%$ in infrared and $1 \%$ at $750 \mathrm{~nm}$. In the retrieved Ångström coefficient and extinction this translates to an error of approximately $10 \%$ near the peak of the aerosol layer.

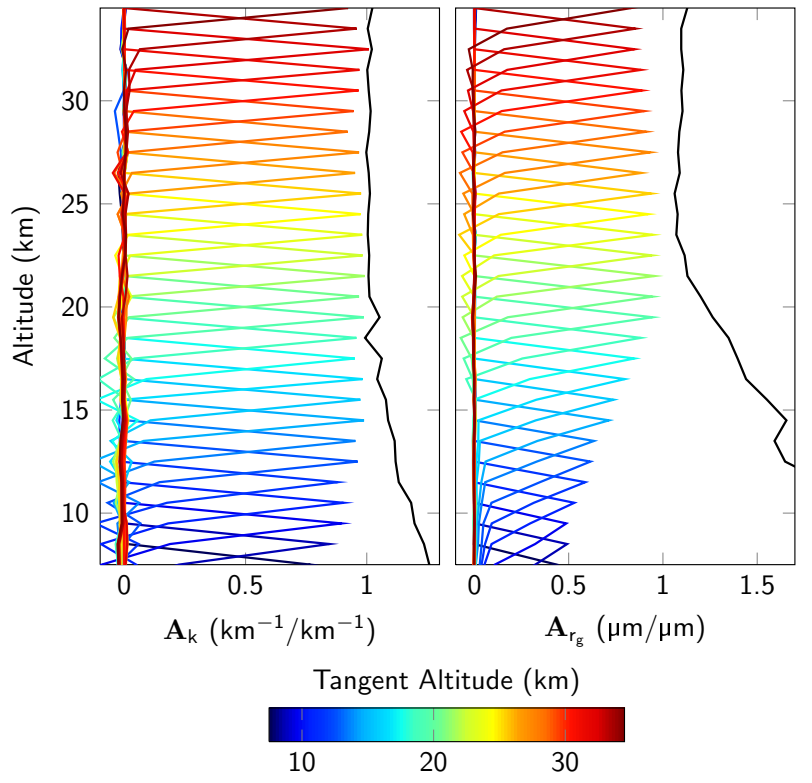

Fig. 8. Averaging kernels for the simulated extinction and mode radius retrievals using lines of sight spaced at $1 \mathrm{~km}$ intervals. Left panel shows the extinction averaging kernels, with the mode radius averaging kernels shown on the right. The black line shows the vertical resolution calculated from the full width at half maximum of the kernels.

\subsection{Smoothing error}

The averaging kernel matrices for the extinction and mode radius quantities are shown in Fig. 8. These are calculated numerically by perturbation of a typical aerosol extinction and mode radius profile at each altitude and successive retrieval using simulated radiances for each state. The averaging kernel is then defined as the change in retrieved state $\hat{\boldsymbol{x}}$ given a change in the true state $x$ :

$\mathbf{A}=\frac{\delta \hat{x}}{\delta \boldsymbol{x}}$.

The smoothing error is then given by

$\boldsymbol{\epsilon}=(\mathbf{A}-\mathbf{I})\left(\boldsymbol{x}-\boldsymbol{x}_{a}\right)$.

For this calculation the a priori extinction is assumed to be zero, as it is initialized at a very small value for the version 5 retrieval, typically a factor of 100 below the retrieved results. The a priori mode radius is $80 \mathrm{~nm}$ at all altitudes.

The averaging kernel for extinction is very nearly unity for $10 \mathrm{~km}$ and above, with very little smoothing of the profile, as was seen in the version 5 algorithm. The resulting smoothing error in extinction is typically less than $5 \%$ for most altitudes, although this increases to more than $10 \%$ below $10 \mathrm{~km}$. Changes in mode radius are not captured as accurately at altitudes below $15 \mathrm{~km}$, with approximately half of the change being added to the perturbed altitude. Despite 


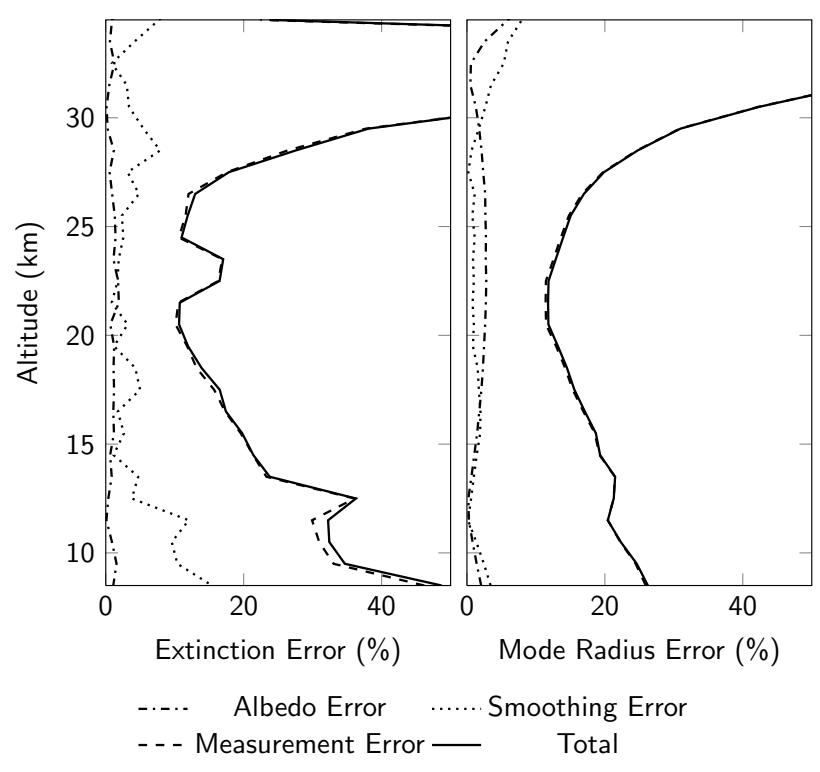

Fig. 9. Total relative error in the retrieved quantities due to albedo, smoothing and measurement error contributions for a simulated measurement with a solar scattering angle of $61^{\circ}$ and a solar zenith angle of $89^{\circ}$. The aerosol profile used in the simulation was typical of background conditions with a mode radius of $80 \mathrm{~nm}$ and a mode width of 1.6. Relative extinction error is shown in the left panel, with the relative mode radius error shown on the right.

the larger off-diagonal elements in the mode radius averaging kernel, error for typical cases are limited to less than $10 \%$ due to more accurate a priori estimates. Note that the magnitude of this error will also depend on geometry and various atmospheric parameters and that this is meant as a representative example case.

\subsection{Albedo error}

One of the largest uncertainties results from the unknown albedo at $1530 \mathrm{~nm}$. Although the albedo is retrieved at $750 \mathrm{~nm}$, the same cannot currently be done at $1530 \mathrm{~nm}$ due to a lack of an absolute calibration in the infrared channels. The immediate solution is to assume the $1530 \mathrm{~nm}$ albedo is equal to that at $750 \mathrm{~nm}$. Because the error due to albedo may be large, it is best to estimate the error through a simulated retrieval. To test a scenario with a large albedo contribution, a scan with a scattering angle of $118^{\circ}$ and zenith angle of $72^{\circ}$ was simulated with an assumed $1530 \mathrm{~nm}$ albedo of 0.5 . For this simulation both the true and assumed $750 \mathrm{~nm}$ albedo was set to 0.5 . OSIRIS measurements were then simulated when the true albedo was 0 and 1 . This produced an error of approximately $15 \%$ in the retrieved extinction and $30 \%$ in the retrieved mode radius, which translates to an error of 10-20\% in the Ångström coefficient depending on particle size. Although OSIRIS geometries exist with smaller zenith angles and larger upwelling contributions

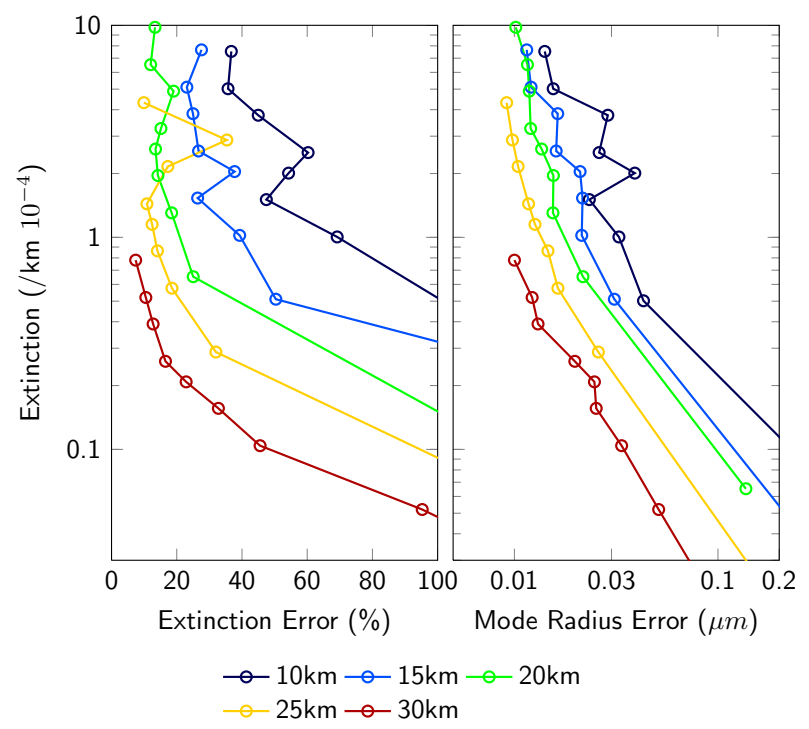

Fig. 10. Error in the retrieved extinction and mode radius parameters due to measurement noise as a function of extinction and tangent altitude. This was calculated by retrieving the error of a typical forward-scatter geometry with varying amounts of aerosol loading.

these geometries have a scattering angle near $90^{\circ}$ increasing the single-scatter contribution as well. Therefore, the precise worst case will depend on many factors; however the geometry chosen here both minimizes the direct aerosol signal and provides substantial albedo contribution, providing a difficult, if not worst-case, scenario. Typical albedo errors are therefore expected to be less than the case studied here, particularly for forward-scattering geometries as can be seen in Fig. 9.

\subsection{Total error}

A scan with a forward-scattering geometry was simulated assuming a typical background aerosol loading, and the relative errors due to measurement, smoothing and $1530 \mathrm{~nm}$ albedo are shown in Fig. 9. At altitudes above $30 \mathrm{~km}$ and below $15 \mathrm{~km}$, error begins to dominate the signal, with virtually all of the error due to measurement noise. In the bulk of the aerosol layer this error reduces to approximately $10-15 \%$ for both retrieved quantities. The error budget is primarily due to the $1530 \mathrm{~nm}$ measurements, which are approximately 510 times noisier than the $750 \mathrm{~nm}$ measurements. The relative and absolute errors due to measurement noise are dependent upon the aerosol concentration due to the decreasing sensitivity of the measurements with increasing optical depth. This effect can be seen in Fig. 3a, where the measurement vector becomes flatter as extinction is increased. The reason for this is that to first order, the increase in aerosol signal scales linearly with increased aerosol, while the attenuation scales exponentially. To test this dependence the aerosol profile was scaled by factors of 0.02 to 3 of the typical value 


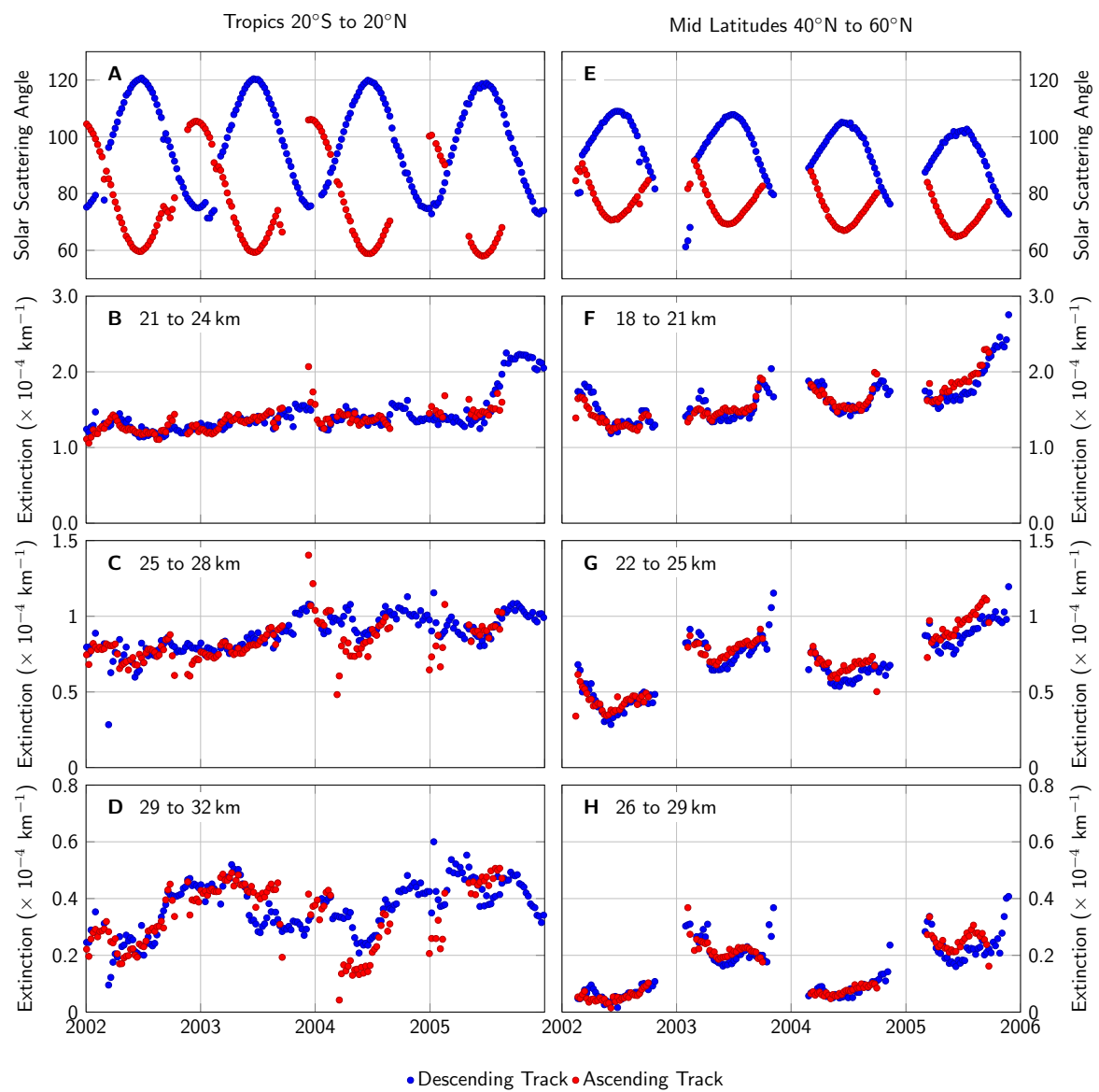

Fig. 11. Same as Fig. 2 except using version 6 data.

and the error retrieved for each case. Results are shown in Fig. 10 for several tangent altitudes. The absolute error in extinction decreases approximately linearly with decreased aerosol loading, with a noise floor of approximately $4 \times 10^{-6}$ at $30 \mathrm{~km}$ increasing to $4 \times 10^{-5}$ at $10 \mathrm{~km}$. However, the relative error increases as aerosol loading decreases, as a smaller fraction of the total signal is due to aerosol scattering. Error in retrieved mode radius is relatively constant, ranging from $0.01 \mu \mathrm{m}$ at $30 \mathrm{~km}$ to $0.04 \mu \mathrm{m}$ at $10 \mathrm{~km}$, provided the extinction is greater than approximately $4 \times 10^{-5} \mathrm{~km}^{-1}$. Although this study was chosen as a typical case, several physical and measurement factors affect the retrieval error including solar scattering angle, solar zenith angle, tangent altitude and particle size as well as the aerosol vertical profile. As such this study is meant to give an estimate of the error involved, but is not comprehensive. Determination of error for additional measurements requires the application of this error analysis on a case-by-case basis.

\section{Results}

\subsection{Retrieval consistency}

The error in the retrieved extinction due to particle size in the version 5 retrievals was evident in internal comparisons between the orbital ascending and descending track measurements, as shown in Sect. 2. This analysis was repeated with results from the coupled particle size retrieval algorithm, shown in Fig. 11. While the scattering angle dependence is clear in the version 5 data, with substantial separation of the ascending and descending track measurements - particularly in the tropics - this is no longer the case with the coupled retrieval, denoted version 6 , with both measurements now retrieving essentially the same aerosol extinction. Although much of the systematic bias has been removed from this data set, each individual measurement now appears noisier. This is due to the inclusion of the $1530 \mathrm{~nm}$ measurements, which are considerably noisier than those from the optical spectrograph. Furthermore, the infrared imager saturates when looking at clouds or thick aerosol layers, particularly in the UT-LS region, due to the increased Rayleigh signal. When this occurs the aerosol retrieval is not attempted below the 


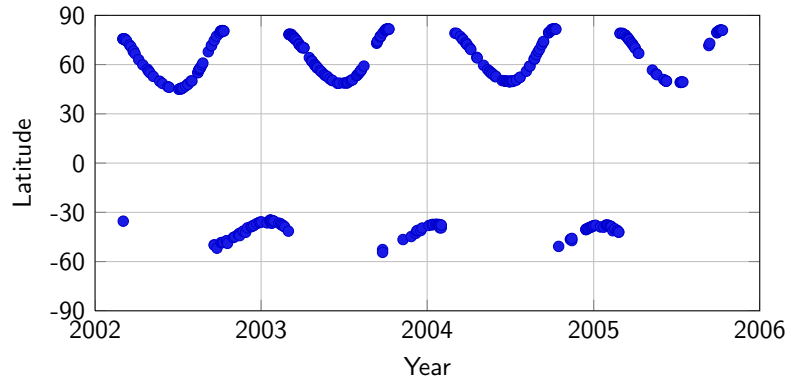

Fig. 12. Location of the SAGE III/OSIRIS coincident measurements as a function of time and latitude.

saturation altitude, but will bias version 6 measurements to times of lower aerosol loading, particularly at lower altitudes during volcanic eruptions.

\subsection{SAGE III recomparison}

During its operation from 2001 until 2005, SAGE III measured aerosol extinction profiles at nine wavelengths, ranging from $385 \mathrm{~nm}$ to $1.54 \mu \mathrm{m}$. SAGE III was launched on the Meteor $3 \mathrm{M}$ platform into a polar orbit, performing occultations in the mid- to polar latitudes. With an accuracy and precision of the order of $10 \%$, and a channel at $755 \mathrm{~nm}$, SAGE III provides an excellent data set for comparison (Thomason et al., 2010). Bourassa et al. (2012) compared the version 5.07 algorithm with coincident SAGE III measurements using a coincident criterion of $\pm 6 \mathrm{~h}, \pm 1^{\circ}$ latitude and $\pm 2.5^{\circ}$ longitude. Due to the SAGE III orbit, coincident profiles occur at welldefined latitudes over the course of a year, as can be seen in Fig. 12.

The average percentage difference between the SAGE III and version 5 OSIRIS measurements separated by year are shown as the solid red lines in Fig. 13; the dashed red lines show one standard deviation. In general, the agreement is quite good, with an average difference typically less than $10 \%$. However, nearly all altitudes in 2005 show a positive bias of up to $20 \%$ with an increased standard deviation. This is likely explained by an inaccurate particle size assumption during the increased aerosol loading caused by the $2004 \mathrm{Mt}$ Manam eruption (Tupper et al., 2007; Vernier et al., 2011).

This comparison was repeated using the same coincident criteria for the version 6 retrievals with results shown in black in Fig. 13. Generally, agreement with the SAGE III measurements is comparable between versions, with typical accuracy of $10-15 \%$. The standard deviation is also similar at approximately $20 \%$ at $15 \mathrm{~km}$, increasing to $50 \%$ by $30 \mathrm{~km}$. Agreement is better in 2005, after the Mt Manam eruption; however version 6 also tends to underestimate extinction from 23 to $30 \mathrm{~km}$. This is particularly evident in 2003. Although these results are promising, the measurements are at mid-to-high latitudes during periods of minimal volcanic influence and so are not expected to be significantly different from the version
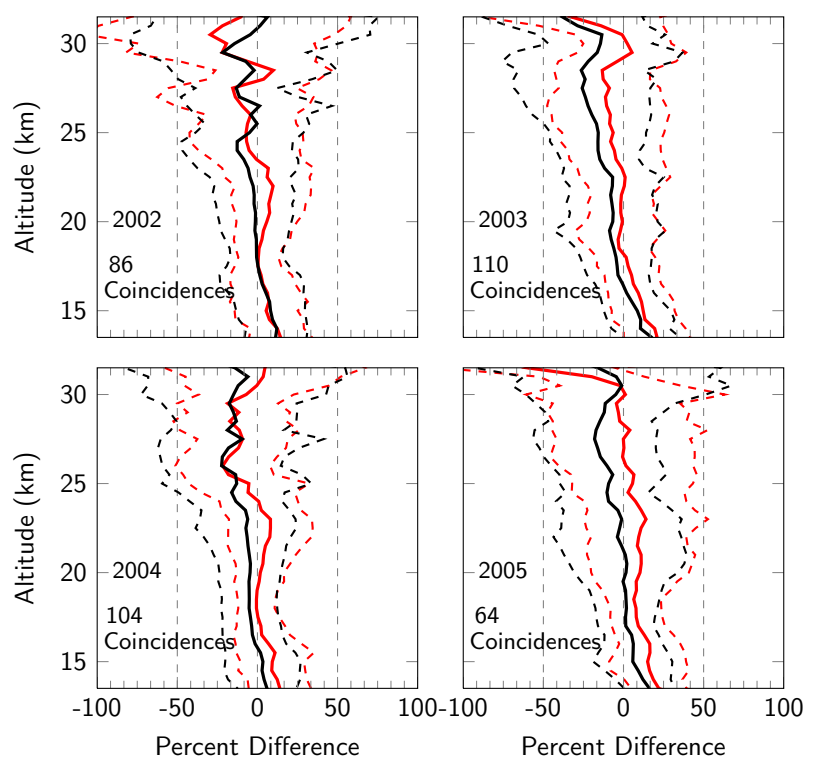

— Version 5 - Version 6

Fig. 13. Comparison of coincident SAGE III $755 \mathrm{~nm}$ aerosol extinction and OSIRIS $750 \mathrm{~nm}$ aerosol extinction. Each panel shows $1 \mathrm{yr}$ of coincident comparisons, with the number of coincident profiles indicated in the respective panel. Mean percentage differences are shown as solid lines with standard deviation shown as dashed. Version 5 retrievals are shown in red, with version 6 shown in black.

5 results. This is evident in Fig. 2, where mid-latitude measurements show much smaller biases between measurement geometries. This shows that despite the noisier IR channel, version 6 still performs as well as version 5, even at mid-tohigh latitudes with minimal volcanic influence.

\subsection{SAGE II comparison}

SAGE II (Russell and McCormick, 1989) was launched in 1985, and continued operating until mid-2005, providing approximately $3 \mathrm{yr}$ of overlap with the OSIRIS mission. SAGE II produced high-quality measurements for the duration of its lifetime with the 525 and $1020 \mathrm{~nm}$ channels, agreeing well with SAGE III for the majority of the aerosol layer (Damadeo et al., 2013). This overlap period also contains good tropical coverage with two volanic periods caused by the eruptions of Mts Ruang (Ru) and Reventador (Ra) in late 2002, and Mt Manam (Ma) in early 2005, providing a good test of the OSIRIS particle size retrieval. Figure 14 shows the retrieved Ångström coefficients in 45-day averages from the SAGE II V7.00A and OSIRIS version 6 data in the tropics for 2002 through 2005. Note that the colour scales are different for the two instruments. In general both show an Ångström coefficient increasing with altitude. Note also the increase in the Ångström coefficients in both data sets after the Ruang/Reventador and Manam eruptions, suggesting an increase in the number of small particles. 

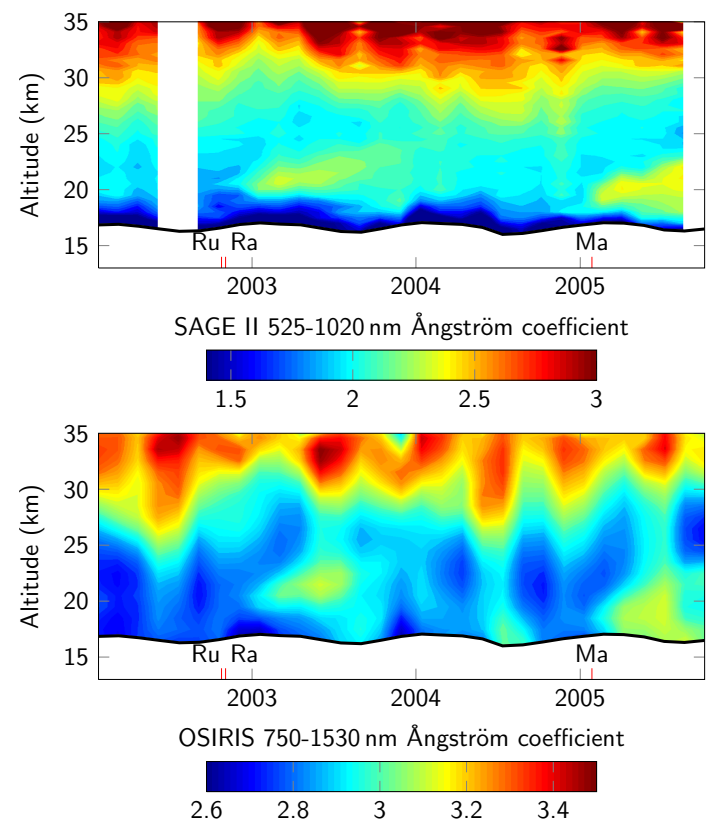

Fig. 14. Comparison of the OSIRIS and SAGE II Ångström coefficients. Top panel shows the SAGE II Ångström coefficient for $20^{\circ} \mathrm{N}$ to $20^{\circ} \mathrm{S}$ in 45 -day averages, calculated from the 525 and $1020 \mathrm{~nm}$ channels. The bottom panel shows the OSIRIS Ångström coefficient for $20^{\circ} \mathrm{N}$ to $20^{\circ} \mathrm{S}$ in 45 -day averages, using the coupled retrieval. Tropopause is denoted by the black line.

Figure 15 shows a cross section of retrieved Ångström coefficients as a function of time and latitude at $22.5 \mathrm{~km}$. In the tropics, increases in the Ångström coefficient 2-3 months after the eruptions of Mts Ruang and Ravenetador in 2002 and Mt Manam in 2005 are visible. Although little, if any, seasonal variation is present in the tropics, a strong seasonal cycle is present in the mid-to-high latitudes with the summer months generally exhibiting the smallest particle sizes.

Although large-scale features agree qualitatively, OSIRIS retrieves a systematically higher Ångström coefficient, particularly at lower altitudes and higher latitudes. Some of this discrepancy is due to the differences in wavelength between the two satellites. The longer OSIRIS wavelengths become optically thick at lower altitudes than the shorter wavelengths, increasing sensitivity in the upper troposphere and lower stratosphere. Also, although extinction is an approximately linear function of wavelength (in log space) this is not strictly true and causes a dependency of the Ångström coefficient on the wavelengths chosen. This can be seen in Fig. 16, where the SAGE II and OSIRIS Ångström coefficients are modelled for a variety of particle sizes. The SAGE II wavelengths show consistently smaller Ångström coefficients by 0.5 to 0.75 when compared to OSIRIS wavelengths. Although the precise difference will depend on the true mode width, making exact determination difficult, this shows that much of the difference is likely due to the wavelength difference of the instruments.
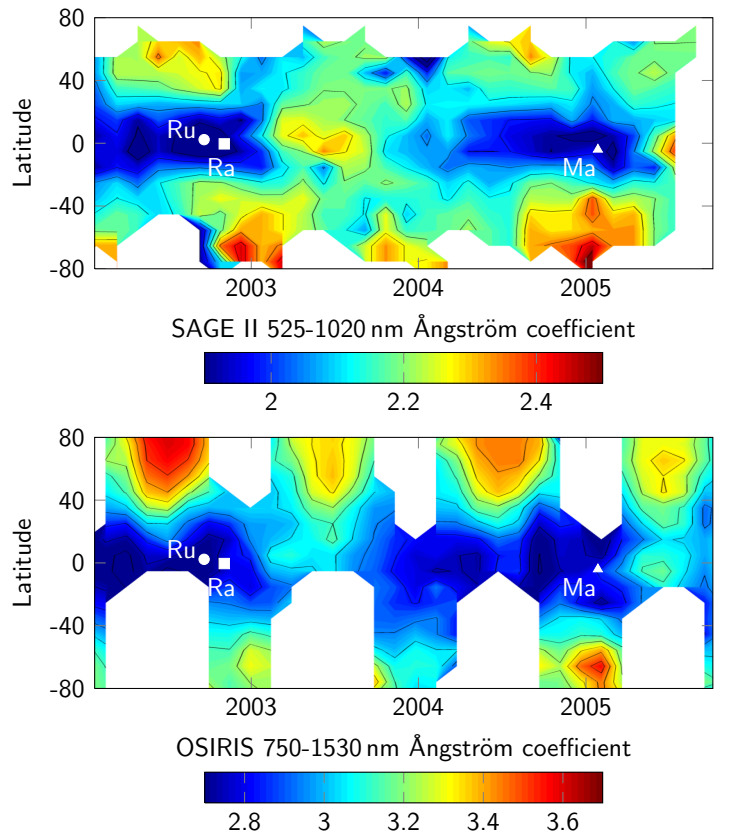

Fig. 15. Comparison of the OSIRIS and SAGE II Ångström coefficients. Top panel shows the SAGE II Ångström coefficient at $22.5 \mathrm{~km}$ in 45-day averages, calculated from the 525 and $1020 \mathrm{~nm}$ channels. The bottom panel shows the OSIRIS Ångström coefficient also at $22.5 \mathrm{~km}$ in 45 -day averages, using the coupled retrieval. Tropopause is denoted by the black line.

The other major sources of error in the Ångström coefficient are the assumed mode width and assumed albedo at $1530 \mathrm{~nm}$. In Sect. 4.1 incorrect microphysical assumptions typically yielded errors of $10 \%$ in the Ångström coefficient. The error due to incorrect albedo will tend to cause larger errors at higher latitudes, as these measurements have larger upwelling contributions due to lower solar zenith angles from the orbital geometry. This is also likely the cause of the apparent 6-month cycle in the tropics above $25 \mathrm{~km}$, visible in Fig. 15, as the solar zenith angle varies biannually at this latitude range. Higher latitudes have a solar zenith angle that varies seasonally, and this may be responsible for the seasonal cycle, which appears stronger in the OSIRIS data than the SAGE II data set. However, from Sect. 4 the Ångström coefficient error is expected to be less than $20 \%$ under typical conditions.

\section{Conclusions}

Through incorporation of the $1530 \mathrm{~nm}$ infrared imager measurement, OSIRIS measurements can be used to retrieve one piece of particle size information. Although incorporation of multiple viewing geometries does add information, for OSIRIS geometries this information is minimal and comes with significant drawbacks in coverage. Using measurements 


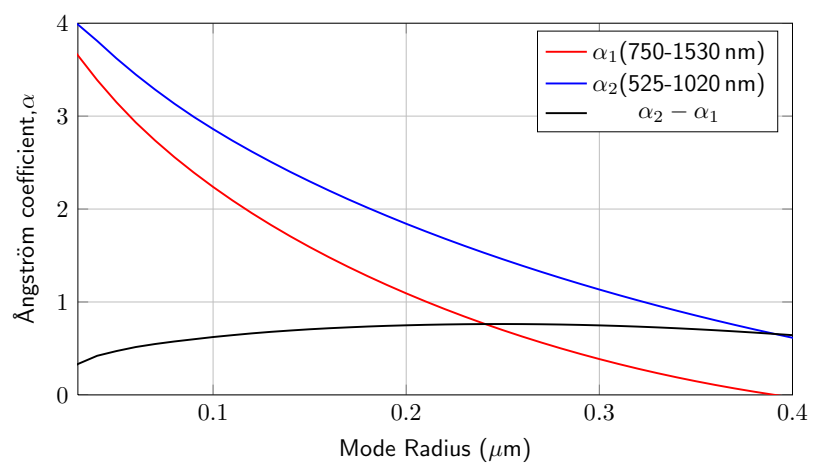

Fig. 16. Comparison of the OSIRIS and SAGE II Ångström coefficients as a function of mode radius for a log-normal distribution with a mode width of 1.6 .

at 750 and $1530 \mathrm{~nm}$, a retrieval algorithm was developed that couples the retrieval of extinction with the mode radius parameter of the log-normal distribution. This reduces the dependence of the retrieved extinction on the assumed aerosol microphysics. Comparison of retrieved extinctions on the ascending and descending orbital tracks show greatly reduced dependence on viewing geometry. Unfortunately, retrievals are now noisier due to the inclusion of the infrared imager measurement and have a tendency to saturate at low altitudes and high aerosol loadings such as in the centre of volcanic plumes. Comparisons with SAGE II show that the retrieved Ångström coefficient is physically realistic in the tropics during both volcanic and non-volcanic periods for the bulk of the stratospheric layer, although the results shows some bias due to the particle size assumptions of a log-normal distribution with a fixed mode width as well as the inability to measure the albedo at $1530 \mathrm{~nm}$. A re-comparison with the SAGE III measurements shows that for mid- to polar latitudes the extinction measurements are in good agreement, particularly during 2005 after the Mt Manam eruption.

\section{Appendix A}

\section{Aerosol kernel derivation}

The derivation of the limb scatter aerosol kernel is easiest to understand by starting from a single-scatter approximation. The single-scatter radiance due to aerosol measured by a limb instrument located at $s_{1}$ along the line of sight $s$, beginning at $s_{0}$ and in the direction $\hat{\Omega}$, is given by

$I\left(s_{1}, \hat{\Omega}\right)=\int_{s_{0}}^{s_{1}} F_{0}(\hat{\Omega}) e^{-\tau(\operatorname{sun}, s)} e^{-\tau\left(s, s_{1}\right)} k_{\text {scat }} \mathrm{p}(s, \Theta) \mathrm{d} s$,

where $k_{\text {scat }}$ is the total scattering extinction, $p(s, \Theta)$ the phase function and $F_{0}$ the solar irradiance. For single scatter the aerosol signal can be separated, and the radiance written as sum of the aerosol, $I_{\text {aer }}$, and Rayleigh, $I_{\text {Ray }}$, contributions:

$I\left(s_{1}, \hat{\Omega}\right)=I_{\text {aer }}\left(s_{1}, \hat{\Omega}\right)+I_{\text {Ray }}\left(s_{1}, \hat{\Omega}\right)$.

The measurement vector from Eq. 6 is then

$y_{\text {aer }}\left(s_{1}, \hat{\Omega}\right)=\ln \left(\frac{I_{\text {aer }}+I_{\text {Ray }}}{I_{\text {Ray }}}\right)$,

since the high-altitude normalization goes to zero for a modelled measurement. Provided the aerosol signal is small compared to the Rayleigh contribution the aerosol measurement vector is

$y_{\text {aer }}\left(s_{1}, \hat{\Omega}\right)=\ln \left(\frac{I_{\text {aer }}}{I_{\text {Ray }}}+1\right)$
$\approx \frac{1}{I_{\text {Ray }}} \int_{s_{0}}^{s_{1}} e^{-\tau(\operatorname{sun}, s)} e^{-\tau\left(s, s_{1}\right)} n_{\text {aer }} \sigma_{\text {aer }} p_{a e r}(s, \Theta) \mathrm{d} s$,

where $F_{0}$ is removed by the high-altitude normalization. Here, the cross section, $\sigma_{\text {aer }}$, and the phase function are the integrated quantities over the range of particle sizes such as

$p_{\text {aer }}(\Theta)=\frac{1}{n_{\text {aer }}} \int_{0}^{\infty} p_{\text {aer }}(\Theta, r) \frac{\mathrm{d} n(r)}{\mathrm{d} r} \mathrm{~d} r$,

where $\mathrm{d} n / \mathrm{d} r$ is the particle size distribution. If attenuation of the incoming solar beam and the along the line of sight is negligible, then the aerosol measurement vector simplifies to

$y_{\text {aer }}\left(s_{1}, \hat{\Omega}\right) \approx \frac{1}{I_{\text {Ray }}} \int_{s_{0}}^{s_{1}} n_{\text {aer }}(s) \sigma_{\text {aer }}(s) p_{\text {aer }}(s, \Theta) \mathrm{d} s$.

Provided the majority of the signal comes from the tangent point shell, this can be further simplified to

$y_{\text {aer }}\left(s_{1}, \hat{\Omega}\right) \approx \frac{1}{I_{\text {Ray }}} n_{\text {aer }} \sigma_{\text {aer }} p_{\text {aer }}(\Theta) \Delta s$,

where $\Delta s$ is the path length through the tangent shell. Equivalently,

$y_{\text {aer }}\left(s_{1}, \hat{\Omega}\right) \approx \frac{\Delta s}{I_{\text {Ray }}} \int_{0}^{\infty} \frac{\mathrm{d} n(r)}{\mathrm{d} r} \sigma_{\text {aer }}(r) p_{\text {aer }}(\Theta, r) \mathrm{d} r$.

The sensitivity, $K_{n}$, of the measurement to a single particle of radius $r$ is then

$K_{n}(r)=\sigma_{\text {aer }}(r) p_{\text {aer }}(\Theta, r) \Delta s$,

the sensitivity to a constant volume is

$K(r)=\frac{3}{4 \pi r^{3}} \sigma_{\mathrm{aer}}(r) p_{\mathrm{aer}}(\Theta, r) \Delta s$, 
and the measurement can then be written

$$
y_{\text {aer }}\left(s_{1}, \hat{\Omega}\right) \approx \frac{1}{I_{\text {Ray }}} \int_{0}^{\infty} K(r) \frac{\mathrm{d} V}{\mathrm{~d} r} \mathrm{~d} r .
$$

Although several approximations were required to obtain this result, a much better estimate of $K$ can be obtained numerically. Rather than assuming $K(r)$ relies solely on the cross section and phase function of aerosols at a particular point, as in Eq. (A7), we can assume it includes all aspects of limb measurements, including attenuation and integration along the rays, upwelling albedo contributions and multiple scatter from aerosols and the Rayleigh background. While this precludes analytic calculation of $K(r)$, the measurement vector, $y_{\mathrm{aer}}$, can be modelled in SASKTRAN using a monodisperse aerosol and Eq. (A11) inverted to yield $K(r)$. While this provides a much better estimate of the kernel, it is not without limitations. The vertical profile of aerosol will affect the kernel due to altitude coupling from multiple scattering as well as integration along the path, and interactions between aerosols of different sizes will not be accounted for. Despite this, the agreement between the very simple single-scatter kernels and the multiple-scatter kernels show that the sensitivity is well described by even the simple model, providing a better understanding of the limb scatter measurements.

Acknowledgements. This work was supported by the Natural Sciences and Engineering Research Council (Canada) and the Canadian Space Agency. Odin is a Swedish-led satellite project funded jointly by Sweden (SNSB), Canada (CSA), France (CNES) and Finland (Tekes).

\section{Edited by: P. K. Bhartia}

\section{References}

Ångström, A.: The parameters of atmospheric turbidity, Tellus, 16, 64-75, 1964.

Barlow, R. J.: Statistics: a Guide to the Use of Statistical Methods in the Physical Sciences, Wiley, England, 1989.

Bourassa, A. E., Degenstein, D. A., Gattinger, R. L., and Llewellyn, E. J.: Stratospheric aerosol retrieval with OSIRIS limb scatter measurements, J. Geophys. Res., 112, D10217, doi:10.1029/2006JD008079, 2007.

Bourassa, A. E., Degenstein, D. A., and Llewellyn, E. J.: Retrieval of stratospheric aerosol size information from OSIRIS limb scattered sunlight spectra, Atmos. Chem. Phys., 8, 63756380, doi:10.5194/acp-8-6375-2008, 2008a.

Bourassa, A. E., Degenstein, D. A., and Llewellyn, E. J.: SASKTRAN: A spherical geometry radiative transfer code for efficient estimation of limb scattered sunlight, J. Quant. Spectrosc. Ra., 109, 52-73, doi:10.1016/j.jqsrt.2007.07.007, 2008b.

Bourassa, A. E., McLinden, C. A., Sioris, C. E., Brohede, S., Bathgate, A. F., Llewellyn, E. J., and Degenstein, D. A.: Fast $\mathrm{NO}_{2}$ retrievals from Odin-OSIRIS limb scatter measurements, Atmos. Meas. Tech., 4, 965-972, doi:10.5194/amt-4-965-2011, 2011.
Bourassa, A. E., Rieger, L. A., Lloyd, N. D., and Degenstein, D. A.: Odin-OSIRIS stratospheric aerosol data product and SAGE III intercomparison, Atmos. Chem. Phys., 12, 605-614, doi:10.5194/acp-12-605-2012, 2012.

Bovensmann, H., Burrows, J. P., Buchwitz, M., Frerick, J., Noël, S., Rozanov, V. V., Chance, K. V., and Goede, A. P. H.: SCIAMACHY: Mission Objectives and Measurement Modes, J. Atmos. Sci., 56, 127-150, doi:10.1175/15200469(1999)056<0127:SMOAMM>2.0.CO;2, 1999.

Damadeo, R. P., Zawodny, J. M., Thomason, L. W., and Iyer, N.: SAGE version 7.0 algorithm: application to SAGE II, Atmos. Meas. Tech., 6, 3539-3561, doi:10.5194/amt-6-3539-2013, 2013.

Degenstein, D. A., Llewellyn, E. J., and Lloyd, N. D.: Tomographic retrieval of the oxygen infrared atmospheric band with the OSIRIS infrared imager, Can. J. Phys., 82, 501-515, 2004.

Degenstein, D. A., Bourassa, A. E., Roth, C. Z., and Llewellyn, E. J.: Limb scatter ozone retrieval from 10 to $60 \mathrm{~km}$ using a multiplicative algebraic reconstruction technique, Atmos. Chem. Phys., 9, 6521-6529, doi:10.5194/acp-9-6521-2009, 2009.

Deshler, T., Hervig, M. E., Hofmann, D. J., Rosen, J. M., and Liley, J. B.: Thirty years of in situ stratospheric aerosol size distribution measurements from Laramie, Wyoming $\left(41^{\circ} \mathrm{N}\right)$, using balloon-borne instruments, J. Geophys. Res., 108, 4167, doi:10.1029/2002JD002514, 2003.

Hofmann, D., Barnes, J., O’Neill, M., Trudeau, M., and Neely, R.: Increase in background stratospheric aerosol observed with lidar at Mauna Loa Observatory and Boulder, Colorado, Geophys. Res. Lett., 36, L15808, doi:10.1029/2009GL039008, 2009.

Llewellyn, E., Lloyd, N. D., Degenstein, D. A., Gattinger, R. L., Petelina, S. V., Bourassa, A. E., Wiensz, J. T., Ivanov, E. V., McDade, I. C., Solheim, B. H., McConnell, J. C., Haley, C. S., von Savigny, C., Sioris, C. E., McLinden, C. A., Griffioen, E., Kaminski, J., Evans, W. F. J., Puckrin, E., Strong, K., Wehrle, V., Hum, R. H., Kendall, D. J. W., Matsushita, J., Murtagh, D. P., Brohede, S., Stegman, J., Witt, G., Barnes, G., Payne, W. F., Piche, L., Smith, K., Warshaw, G., Deslauniers, D. L., Marchand, P., Richardson, E. H., King, R. A., Wevers, I., McCreath, W., Kyrola, E., Oikarinen, L., Leppelmeier, G. W., Auvinen, H., Megie, G., Hauchecorne, A., Lefevre, F., de La Noe, J., Ricaud, P., Frisk, U., Sjoberg, F., von Scheele, F., and Nordh, L.: The OSIRIS instrument on the Odin spacecraft, Can. J. Phys., 82, 411-422, doi:10.1139/p04-005, 2004.

Marquardt, D. W.: An algorithm for least-squares estimation of nonlinear parameters, J. Soc. Ind. Appl. Math., 11, 431-441, available at: http://www.jstor.org/stable/2098941 (last access: 4 June 2013), 1963.

Rault, D. F.: Ozone profile retrieval from Stratospheric Aerosol and Gas Experiment (SAGE III) limb scatter measurements, J. Geophys. Res.-Atmos., 110, D09309, doi:10.1029/2004JD004970, 2005.

Rault, D. and Loughman, R.: Stratospheric and upper tropospheric aerosol retrieval from limb scatter signals, Proc. SPIE 6745, doi:10.1117/12.737325, 2007.

Rault, D. F. and Loughman, R. P.: The OMPS Limb Profiler Environmental Data Record Algorithm Theoretical Basis Document and Expected Performance, 2013.

Rieger, L. A.: Stratospheric Aerosol Particle Size Retrieval, 2013. M.Sc. thesis, University of Saskatchewan. 
Rodgers, C. D.: Inverse methods for atmospheric sounding: theory and practice, World Scientific, Singapore, 2000.

Russell, P. B. and McCormick, M. P.: SAGE II aerosol data validation and initial data use - an introduction and overview, J. Geophys. Res., 94, 8335-8338, doi:10.1029/JD094iD06p08335, 1989.

Thomason, L. W. and Poole, L. R.: Use of stratospheric aerosol properties as diagnostics of Antarctic vortex processes, J. Geophys. Res., 98, 23003-23012, doi:10.1029/93JD02461, 1992.

Thomason, L. W., Poole, L. R., and Deshler, T.: A global climatology of stratospheric aerosol surface area density deduced from Stratospheric Aerosol and Gas Experiment II measurements: 1984-1994, J. Geophys. Res., 102, 8967-8976, doi:10.1029/96JD02962, 1997.

Thomason, L. W., Moore, J. R., Pitts, M. C., Zawodny, J. M., and Chiou, E. W.: An evaluation of the SAGE III version 4 aerosol extinction coefficient and water vapor data products, Atmos. Chem. Phys., 10, 2159-2173, doi:10.5194/acp-10-2159-2010, 2010.

Tupper, A., Itikarai, I.,Richards, M.,Prata, F.,Carn, S., and Rosenfeld, D.: Facing the Challenges of the International Airways Volcano Watch: The 2004/05 Eruptions of Manam, Papua New Guinea, Weather Forcast. 22, 175-191, doi:10.1175/WAF974.1, 2007.

Twomey, S.: Introduction to the Mathematics of Inversion In Remote Sensing and Indiret Measurements, Elsevier Scientific Publishing Company, New York, 1977.
Uchino, O., Sakai, T., Nagai, T., Nakamae, K., Morino, I., Arai, K., Okumura, H., Takubo, S., Kawasaki, T., Mano, Y., Matsunaga, T., and Yokota, T.: On recent (2008-2012) stratospheric aerosols observed by lidar over Japan, Atmos. Chem. Phys., 12, 1197511984, doi:10.5194/acp-12-11975-2012, 2012.

Vernier, J.P., Thomason, L.W., Bourassa, A., Pelon, J., Garnier, A., Hauchecorne, A., Blanot, L., Trepte, C., Degenstein, D., and Vargas, F.: Major influence of tropical volcanic eruptions on the stratospheric aerosol layer during the last decade, Geophys. Res. Lett., 38, L12807, doi:10.1029/2011GL047563, 2011.

von Savigny, C., Haley, C. S., Sioris, C. E., McDade, I. C., Llewellyn, E. J., Degenstein, D., Evans, W. F. J., Gattinger, R. L., Griffioen, E., Kyrölä, E., Lloyd, N. D., McConnell, J. C., McLinden, C. A., Mégie, G., Murtagh, D. P., Solheim, B., and Strong, K.: Stratospheric ozone profiles retrieved from limb scattered sunlight radiance spectra measured by the OSIRIS instrument on the Odin satellite, Geophys. Res. Lett., 30, 1755, doi:10.1029/2002GL016401, 2003.

Yue, G. K., Lu, C.-H., and Wang, P.-H.: Comparing aerosol extinctions measured by Stratospheric Aerosol and Gas Experiment (SAGE) II and III satellite experiments in 2002 and 2003, J. Geophys. Res., 110, D11202, doi:10.1029/2004JD005421, 2005. 